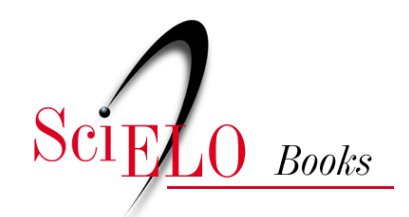

\title{
Urbanismo imperial e planejamento dos barões a formação da cidade de Petrópolis (RJ) nas origens do processo urbanístico brasileiro
}

\author{
Ana Paula Silva de Araújo
}

\section{SciELO Books / SciELO Livros / SciELO Libros}

ARAÚJO, A.P.S. Urbanismo imperial e planejamento dos barões: a formação da cidade de Petrópolis (RJ) nas origens do processo urbanístico brasileiro. In: MARAFON, G.J., and RIBEIRO, M.A. orgs. Revisitando o território fluminense, VI [online]. Rio de Janeiro: EDUERJ, 2017, pp. 291-303. ISBN: 978-85-7511-457-5. https://doi.org/10.7476/9788575114575.0015.

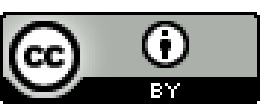

All the contents of this work, except where otherwise noted, is licensed under a Creative Commons Attribution 4.0 International license.

Todo o conteúdo deste trabalho, exceto quando houver ressalva, é publicado sob a licença Creative Commons Atribição $\underline{4.0}$.

Todo el contenido de esta obra, excepto donde se indique lo contrario, está bajo licencia de la licencia Creative Commons $\underline{\text { Reconocimento } 4.0 .}$. 


\section{Urbanismo imperial e planejamento dos barões: a formação da cidade de Petrópolis (RJ) nas origens do processo urbanístico brasileiro}

Ana Paula Silva de Araújo

\section{Introdução}

E ste texto teve origem na dissertação intitulada "Ideologia, patrimônio e memória na (re)produção do planejamento urbano e das políticas culturais e de preservação na cidade imperial de Petrópolis (RJ)”. Visa-se, com este trabalho, compreender as raízes do processo urbanístico brasileiro, tomando como ponto de partida a cidade do Rio de Janeiro, que foi o principal palco da chegada de muitas ideias, além de haver recebido muitos investimentos em infraestrutura urbana.

Assim, tomando-se a cidade do Rio de Janeiro como ponto de partida para entender o nascimento do processo urbanístico no Brasil, analisa-se como esse processo influenciou outras localidades para além dos limites da cidade do Rio, ou seja, especificamente como foram pensados o planejamento e a fundação da cidade de Petrópolis, uma cidade que congregou o urbanismo imperial e o planejamento dos barôes, pertencentes, respectivamente, à concepção da Cidade Nova e da Fazenda de Santa Cruz.

Busca-se, aqui, aprofundar as origens do processo urbanístico no Brasil, tentando entender sua relação com a vinda da Família Imperial e as transformaçōes ocorridas no espaço urbano do Rio de Janeiro, com destaque para o pensamento dos engenheiros militares e dos higienistas. Autores como Andrade (1966) e Fernandes (2008) não foram citados na dissertação, pois o objetivo não era detectar as origens do processo urbanístico brasileiro, nem tampouco e o que distinguia as cidades coloniais portuguesas no Brasil das cidades hispânicas. Foram consultados outros autores, a fim de dar novas e mais profundas contribuições em relação à cidade de Petrópolis.

Nesse contexto, indaga-se: "Quais origens do processo urbanístico brasileiro - que teve a cidade do Rio de Janeiro como centro irradiador de cultura e informações - contribuíram para o planejamento de uma cidade-palácio como Petrópolis?”. Refletir acerca das origens do pensamento urbanístico brasileiro implica contribuir para se repensar o presente com base no passado, com vistas a superar, no futuro, certas correntes e organizaçóes que contribuem cada vez mais para a desigualdade social no espaço urbano que habitamos. 


\section{Urbanismo imperial e planejamento dos barões no processo urbanístico brasileiro}

Para tratarmos, em linhas gerais, do processo urbanístico brasileiro, recorremos a Andrade (1966), autor que faz um levantamento histórico significativo das principais transformações e atores sociais na morfologia de nossas cidades. Para esse estudioso, a presença de dom João VI, a chegada da Família Imperial Portuguesa ao Brasil e a abertura dos portos desempenharam papel relevante no processo urbanístico brasileiro. O certo é que a presença da corte transformou o Rio de Janeiro em um "foco de irradiação de cultura e de civilização" (Andrade, 1966, p. 107). A chegada de instituições, de novos códigos sociais e de equipamentos culturais quando da transferência da corte para o Brasil ganha importância, e Andrade (1966) nos auxilia a entender como se delineou o processo urbanístico brasileiro.

Assim, ao examinar as transformações urbanísticas provocadas pela chegada da corte ao Brasil, Andrade (1966) afirma que as "primeiras tentativas brasileiras no campo do planejamento econômico e territorial” se devem à figura do Visconde de Cairu, pois, em decorrência de suas ideias e açóes, foi possível expandir algumas áreas e a população das cidades (Andrade, 1966). Outro personagem importante foi o Conde dos Arcos, que esteve à frente de grandes melhoramentos públicos e de saneamento, da construção do Teatro São João, entre outros (Andrade, 1966). Ele foi também responsável pela desocupação de imóveis para a acomodação da corte recém-chegada ao Brasil (Abreu, 2014).

Os investimentos em infraestrutura na cidade do Rio de Janeiro visavam que a capital do vice-reino perdesse o aspecto de colônia, de atraso. Assim, contando com a participação de arquitetos e engenheiros em cargos públicos, foram realizadas várias obras, o que nos dá a entender que, através desses feitos, eles impulsionavam os primórdios do processo urbanístico brasileiro. Muitos cargos eram criados para operacionalizar as inúmeras obras e os diversos planos, como, por exemplo, os de arquiteto real e arquiteto das reais obras públicas - que, na época de D. Pedro I, eram chamados de arquiteto da nova inspeção da corte do Rio de Janeiro e arquiteto das obras nacionais e imperiais - e de arquiteto do Senado da Câmara, em substituição à função de mestre geral d'obras públicas, arruador e arquiteto do Senado da Câmara (idem).

Entre os muitos profissionais citados por Andrade (1966), citamos o arquiteto Manuel da Costa (1808 a 1826), responsável pela ordenação arquitetônica e espacial da Quinta da Boa Vista, e o engenheiro José de Souza Soares de Andréia (barão de Caçapava), que efetuou um levantamento das plantas da cidade do Rio de Janeiro, incluindo as de Copacabana. Além dessas duas figuras, segundo Andrade (1966, p. 111),

Morales de los Rios Filho identifica cerca de 50 arquitetos e engenheiros que exerceram funções de ordenação urbana, além do exercício profissional como projetistas e construtores. Os arquitetos dos edifícios administrativos, dos palácios, dos solares e residências foram os maiores modificadores da paisagem urbana carioca, responsáveis, sem dúvida, pelo uso mais racional e o trato mais atualizado dos espaços públicos e pela melhor ordenação física da cidade nos primeiros anos da independência. 


\section{Urbanismo imperial e planejamento dos barões}

Um arquiteto que não pode ser esquecido é Augusto Henri-Victor Grandjean de Montigny (1776-1850), que, de acordo com Andrade (idem, pp. 111-2), procedeu à abertura de avenidas, à regularização de ruas tortas, a construção de projetos de ligação viária entre São Cristóvão, Campo de Santana e Cais de Pina, à projeção de chafarizes para o abastecimento de água da cidade, à ordenação espacial e arquitetônica do Largo do Valongo e a muitas outras realizações. O Rio de Janeiro era, como afirma Abreu (1997, p. 35), "uma cidade apertada" e limitada pelos morros do Castelo, de São Bento, de Santo Antônio e da Conceição. E a ocupação de determinadas partes se dava em função do dessecamento de brejos e mangues (idem, ibidem). Por isso, havia necessidade de um grandioso sistema de engenharia para ocupá-la e adaptá-la aos anseios de uma corte transferida do Velho Mundo. Afinal de contas, como bem afirmou Abreu (2014, p. 363), embora "[...] outras cidades coloniais, como Calcutá, Sydney ou Cairo, possam ter tido aspirações imperiais, elas próprias nunca assumiram o papel de metrópoles imperiais".

Quanto às obras e aos planos associados à alteração da morfologia urbana, destaca-se a promoção de saneamento nos pântanos do Rio de Janeiro, em 1648, que foi o aterro da Lagoa do Desterro e dos mangueirais da cidade baixa (Andrade, 1966). No governo de Gomes Freire (1733-1762), foram realizadas muitas obras nos grandes mangueirais da Cidade Nova pelo Marquês de Lavradio, em 1770. Ainda houve o melhoramento do Passeio Público por d. Luiz de Vasconcelos, que limpou praias e aterrou a faixa marítima, como bem afirmou Andrade (1966).

Na cidade de São Paulo, destaca-se o engenheiro Mar. Daniel Pedro Muller, que trabalhava no saneamento das várzeas, fazendo também um levantamento cadastral e uma planta da cidade. Esse engenheiro mostrou, por meio de sua atuação no início da urbanização paulista, a necessidade de se pensar numa legislação apropriada dos quadros administrativos, contando-se com profissionais da área, no intuito de se obterem resultados programados (Andrade, 1966, pp. 114-5).

O fato é que "as velhas e novas cidades brasileiras" estavam, pouco a pouco, deixando de ser transformadas apenas por portadores de diplomas legais pertencentes à metrópole. Lembramos que, para além da Constituição de 1834 e da Lei de $1^{\circ}$ de outubro de 1828 do Regimento das Câmaras Municipais, as posturas municipais exercidas até a República tomavam por base a antiga Ordenação Filipina (Andrade, 1966, p. 115). A vinda da Missão Artística Francesa de 1816, a formação de novos profissionais em escolas primárias e normais de 1835 em diante, a existência de liceus de artes e ofícios depois de 1856, da Academia Imperial de Medicina em 1829 e do Instituto dos Advogados em 1843 (idem, p. 116), tudo isso contribuiu para a formação dos profissionais envolvidos no processo urbanístico brasileiro.

Sérgio Buarque de Hollanda, Nestor Goulart Reis e Maurício de Almeida Abreu, entre outros, assinalam o aspecto aparentemente desleixado e de atraso das cidades brasileiras em suas plantas, mostrando o começo de sua configuração territorial ainda sob o domínio da metrópole portuguesa. Concordamos com Abreu (2014) no sentido de que as cidades brasileiras não são obra do acaso dos portugueses, que não planejavam suas cidades com planos retilíneos e a localização estratégica de determinados elementos, como, por exemplo, uma praça central. Havia uma estratégia geopolítica que reforçava o papel do Estado português que, como aponta Abreu (2014),

[...] teve um papel muito mais importante na organização territorial e urbana da colônia do que aquele que é geralmente admitido. A fundação de núcleos urbanos nas áreas de fronteira com a América Espanhola durante o século XVIII, 
por exemplo, sempre foi explicada pela historiografia brasileira como evidência da adoção de critérios nitidamente geopolíticos na orientação do processo de ocupação do território (pp. 234-5).

Nélson da Nóbrega Fernandes (2008) afirma que as críticas às cidades brasileiras faziam referência a falta de planejamento, desleixo e formação espontânea, graças à nossa herança portuguesa, algo semelhante ao urbanismo islâmico e medieval. No entanto, não faltam evidências da existência de cidades planejadas com plantas que mostram ruas de traçado retilíneo, com praças e uma setorização quanto à localização de cemitérios e igrejas, bem como em relação à moradia de determinadas classes sociais. No entanto, esses não são os únicos fatores que nos permitem entender e considerar uma cidade como planejada. Devemos atentar também para as lógicas distintas e para as estratégias de expressão espacial de cada cidade. Assim, de acordo com Fernandes (2008),

[...] Procurava-se estabelecer padrões de comportamento mais disciplinados, somados à apreciação estética centrada no conceito da perspectiva oriunda do Renascimento Italiano, que exigia uma arrumação dos objetos arquitetônicos e urbanos de modo que se apresentassem diante do observador expondo a lógica do mundo vigente. A paisagem construída exercia, assim, uma função pedagógica, afirmando na frente de todos os princípios esclarecidos e vigilantes do Estado policial. A avenida permitia tanto a contemplação do palácio como o espetáculo das paradas militares ou o rápido deslocamento das tropas em situações de distúrbio. As praças retangulares foram delimitadas por uma sequência de fachadas que repetiam o mesmo estilo arquitetônico, criando um espaço fechado e simétrico quando visto de qualquer de seus ângulos, como se registra em casos das praças reais de Madri e Paris. Ao contrário da cidade medieval, cuja morfologia heterogênea, complicada e surpreendente exige uma compreensão lenta através de suas diferentes perspectivas, para o ideal do urbanismo barroco a cidade deve aparecer e ser vista de um só golpe.

Qualquer que tenha sido a estratégia das cidades de colonização hispânica e colonização portuguesa, não devemos comparar seus traçados urbanos, que nos impóem duas realidades em que o Poder Imperial se fazia presente no urbano. $\mathrm{O}$ traçado irregular, as ruas tortuosas e as áreas edificadas em relevos acidentados de cidades como o Rio de Janeiro nos mostram uma imagem facilmente associada ao que Abreu (2014, p. 240) denominou como "soluçóes provisórias", que eram adotadas pela iniciativa local das câmaras municipais na longa espera pelas decisóes da Coroa.

O processo urbanístico praticado a partir da chegada da Família Imperial Portuguesa ao Brasil se dava em torno de duas correntes de pensamento urbano, que, segundo Abreu (2014, pp. 241-2), eram o "pensamento dos engenheiros militares" e o "pensamento higienista", os quais estiveram presentes nas intervenções do espaço urbano e perduraram por boa parte do Brasil oitocentista. Ainda segundo Abreu, o primeiro pensamento tinha a cidade como um espaço a ser defendido, vigiado e controlado pela polícia. O segundo, por sua vez, também defendia a necessidade de controle, focando-se ainda na preservação da população pelo Estado com a adoção de medidas médicas. $\mathrm{O}$ pensa- 


\section{Urbanismo imperial e planejamento dos barões}

mento higienista chegou ao Brasil com a vinda da Família Imperial Portuguesa. Abreu explica bem o contexto no qual esse pensamente se insere (2014, pp. 242-3).

A deterioração da qualidade de vida de grande parte da população europeia, a partir da Revolução Industrial, veio reforçar bastante o pensamento higienista. Tentando dar uma resposta às epidemias que assolavam as grandes cidades, os médicos não hesitaram em associá-las a diversos elementos do quadro natural circundante, que seriam os principais causadores das doenças. Entre os grandes vilōes do meio ambiente, destacavam-se os pântanos, elo de ligação entre as "entranhas da Terra" e a "atmosfera", os quais, sendo locais de putrefação de matéria orgânica, acabavam por produzir uma série de "vapores" prejudiciais à saúde, que seriam depois disseminados pelos ventos para outros locais. Esses vapores, chamados de miasmas, eram os verdadeiros causadores das epidemias, mas sua ação patológica era também facilitada pelas péssimas condiçōes de higiene verificadas nas cidades.

Segundo Andrade (1966), a realização de grandes obras de saneamento nas cidades brasileiras, com o intuito de também conter os surtos de febre amarela e cólera, e de combater a insalubridade urbana, contou com figuras como Francisco de Paula Cândido, presidente da Junta Central de Higiene Pública de 1851 a 1863. Cândido foi responsável por recomendar a fundação de hospitais de isolamento e a construção de cemitérios públicos. Destacam-se ainda os médicos Joaquim Antônio de Medeiros, Francisco Lopes de Oliveira Araújo, Luiz de Oliveira Bueno e Alfredo de Sá Pereira, que trabalharam nos campos da climatologia e da topografia entre os anos de 1815 e 1880 (Andrade, 1966). Em 1849, a Comissão de Higiente Pública da Província de Pernambuco publicou importantes trabalhos a respeito da salubridade em Recife.

Nesse contexto, observa-se que essas duas correntes do pensamento urbano compuseram a essência do processo urbanístico no Brasil, que pode ser vista pelo traçado irregular das cidades, pelas já mencionadas "soluções provisórias" e pela realização das obras públicas de saneamento. Também devemos considerar a construção de residências para o monarca e sua corte, que, ao lado da imposição de novos códigos sociais e do intenso investimento na infraestrutura da cidade, compôs aquilo que denominamos urbanismo imperial e planejamento dos baróes (Fridman, 2009). Esse quadro nos ajuda a definir o que, com a chegada da Coroa portuguesa ao Brasil, em um primeiro momento, representou o processo urbanístico brasileiro.

Urbanismo imperial e planejamento dos barôes são expressões utilizadas por Fridman (idem, p. 140) que se referem aos programas de intervenção observados na morfologia urbana e nas políticas de gestão do território nos estudos de caso da Cidade Nova e da Fazenda Santa Cruz.

Entendida no contexto do urbanismo imperial, para Fridman (idem, p. 143), a Cidade Nova,

[...] erigida depois da chegada da família real, não seria um espraiamento do tecido urbano. As açóes naquele território refletiam o desejo de se implantarem hábitos civilizados e firmar o centro de poder da capital do império português através de uma nova imagem que se intentava imprimir em contraposição à cidade velha. Pode-se interpretá-la ainda como uma resposta à urbe sitiada pela subcidade africana que era o Valongo. Ou seja, no novo sítio nasceu uma nova cidade, fruto 
da autonomia econômica dos ricos, que necessitavam de espaço para a sua vida semiurbana com sabor rural, com senzala, chiqueiro, estrebaria, cocheira, horta, pomar e viveiro. Também originada pela difícil comunicação com os engenhos e fazendas, foi retrato da concepção iluminista do projeto político liberal.

O urbanismo imperial estava atrelado à corrente urbana do higienismo com um traçado regular e também deveria reafirmar o poder da metrópole inaugurando os novos hábitos e costumes de um novo modo de vida urbano que deveria instaurar a civilização na colônia. De acordo com Fridman, a Cidade Nova foi um antigo caminho semirrural que ligava o Palácio da Quinta da Boa Vista ao Paço da Cidade. Esse antigo caminho foi adaptado para a passagem de carruagens, chamando-se "Aterrado" ou "Caminho das Lanternas", sendo, posteriormente, transformado nas ruas de São Pedro da Cidade Nova e Senador Eusébio.

Fridman (2009) também afirma que a aparência fétida da cidade, com seus pântanos e brejos, além da presença de escravos, levou o rei a promover obras para desinfetá-la, de modo a ter maior visibilidade para as chácaras que se situavam nos arredores.

[...] Com os charcos dessecados, a edificação de solares e a estruturação da nova sede política abrigando as repartições governamentais, o entorno do Campo de Santana tornou-se nobre, modificando-se sua composição socioeconômica e consolidando-se a ocupação da região, que passou a denominar-se Cidade Nova (p. 142).

Portanto, o urbanismo imperial estava atrelado ao projeto de civilização da colônia, buscando caminhos para uma reflexão urbana higienista. A Cidade Nova, portanto, é apenas um dos muitos exemplos dessa prática.

Em relação ao planejamento dos barôes, relacionado à Fazenda de Santa Cruz, Fridman (2009) cita a distribuição de sesmarias entre determinados segmentos sociais, o que acabou por dar origem a essa propriedade, que, no passado, pertencia aos jesuítas. A Fazenda de Santa Cruz foi a terceira residência dos imperadores, sucedida pelo Palácio Imperial de Petrópolis. A primeira havia sido o Paço da Cidade e a segunda, o Palácio da Quinta da Boa Vista (Lacombe, 2007).

À exceção do Paço da Cidade, os outros palácios serviram para a prática da vilegiatura dos imperadores. A vilegiatura, segundo Ambrozio (2005), deriva de villla, que seria a casa italiana de campo, a villa do ócio dos romanos. Segundo Fridman (2009), as villas de recreio nos arredores da cidade serviam para os ricos, sem saírem da cidade, desfrutarem de contato direto com a natureza.

Nesse sentido, o urbanismo imperial e o planejamento dos barôes não devem ser vistos separadamente, como se fossem dois processos espaciais distantes, pois, juntos, configuraram, em sua morfologia e na lógica de produção do espaço urbano, a gênese do processo urbanístico brasileiro. Em outras palavras, Fridman (2009, p. 148) considera que o urbanismo imperial consolidou a Cidade Nova segundo os moldes higienistas e que a Fazenda de Santa Cruz foi pensada de acordo com a lógica do planejamento dos barōes, criando-se uma povoação que funcionaria como um núcleo para trabalhar com manufatura. 
Assinala-se que a construção de palácios para a prática da vilegiatura dos imperadores e os investimentos em infraestrutura urbana conforme os moldes higienistas não ficariam restritos aos limites da cidade do Rio de Janeiro, acompanhando a descoberta de novos caminhos para a subsequente implantação do projeto de civilização.

\section{Novos caminhos e uma cidade-palácio: a ocupação da região serrana fluminense e o processo urbanístico da cidade de Petrópolis (RJ)}

Segundo Silva (2000), a colonização da região serrana se deu a partir do século XVIII, com a finalidade de se buscar um caminho mais seguro em direção ao porto do Rio de Janeiro e às novas rotas para as Minas Gerais. Isso porque havia apenas um caminho de comunicação, conhecido como "Caminho Velho", que seguia pelos sertôes do Rio de Janeiro até a regiāo do ouro em Minas Gerais.

Em 1699, o capitão-mor Garcia Rodrigues Pais finalizou as obras do "Caminho Novo”, o qual, embora proporcionasse economia de tempo para se chegar às minas, somente ganhou importância no cultivo do café e do algodão na província mineira. $\mathrm{O}$ atalho do Caminho Novo, que veio a ser o Caminho Real das Minas Gerais, ou Caminho da Estrela, foi aquele aberto pelo sargento-mor Bernardo Soares de Proença, que percorria o vale do rio Piabanha em direção ao porto da Estrela, no rio Inhomirim, no fundo da Baía de Guanabara. Esse caminho encurtava ainda mais a viagem, com a vantagem de estar num terreno menos acidentado (Silva, 2000).

A abertura do atalho do Caminho Novo, que levou à descoberta das terras que viriam a ser a cidade de Petrópolis, fez com que surgissem sesmarias em todo o seu percurso, no vale do rio Piabanha e em seus afluentes. Ao todo, foram oito sesmarias, que corresponderiam à área atual da cidade de Petrópolis. O grande incentivador da ocupação dessa localidade, como já assinalado, foi o sargento-mor Bernardo Soares de Proença, que influenciou amigos e parentes a se fixarem naquele local, a fim de fortalecer uma rede social no domínio e na conquista dessas terras.

As oito sesmarias que correspondem à cidade de Petrópolis, incluindo todos os seus distritos e São José do Vale do Rio Preto (Silva, 2000), eram medidas por quadras. Essas quadras eram a "Quadra das Pedras"; a "Quadra de Araras"; a "Quadra do Rio Morto", de onde surgiu a Fazenda do Padre Correia, a mais importante fazenda da região de "serra acima”; a "Quadra da Paciência"; a "Quadra do Alcobaça", de onde surgiram a Fazenda da Samambaia e a Capela de Nossa Senhora da Conceição, pertencente ao sobrinho do Padre Correia, Luiz Gonçalvez Dias Correia; e a "Quadra do Rio Preto", o que vem a ser o município de São José do Vale do Rio Preto, antigo quinto distrito de Petrópolis.

A “Quadra de Itamarati”, pertencente ao primeiro sesmeiro da região, Bernardo Soares de Proença, localizada no vale do rio Itamarati, afluente do Piabanha, corresponde ao que conhecemos hoje como o centro urbano de Petrópolis. Vários sítios e fazendas se originaram dessa sesmaria, como a Fazenda do Córrego Seco e a Fazenda do Itamarati (Silva, 2000). A Fazenda do Córrego Seco era um local de pernoite para os viajantes. O Padre Correia, proprietário da fazenda, era um dos principais lavradores de sua época que mantinham comércio com a capital. 
O palácio de D. Pedro I teve sua construção idealizada na Fazenda do Córrego Seco, situada na Serra da Estrela, na rota de Minas Gerais, que Montalvão (2005) também recuperou em seu trabalho. Essa seria a localidade precisa para receber a construção de um palácio. Nesse mesmo cenário de descobrimentos e aforamentos de diversas terras, e da abertura de novas rotas para o caminho até Minas Gerais, uma malha administrativa foi configurada, e novos arranjos espaciais foram surgindo.

O certo é que Córrego Seco, antes de ser município de Petrópolis, pertencera a Magé, Cantagallo, Parahyba do Sul e Estrella (Lacombe, s.d., p. 73). O município de Cantagallo fora criado por uma lei de 9 de março de 1814, tendo seu arraial e o distrito das Novas Minas de Cantagallo promovidos a vila, a Villa de S. Pedro de Cantagallo.

Com a criação da Villa de Parahyba do Sul, em 1833, foram incorporados ao seu território a freguesia de S. José do Rio Preto e o Córrego Seco. A Lei n. 397, de 20 de maio de 1846, contudo, alterou esse território, criando mais uma freguesia, São Pedro de Alcântara, que se separou da freguesia de São José do Rio Preto, a qual, por sua vez, passou a pertencer à Villa da Estrella, tendo o cônego Luiz Gonçalves Dias Corrêa como vigário e proprietário da Fazenda da Samambaia.

Seguindo com a história de seu território administrativo, foi em 1857 , por meio da Lei n. 961, que Petrópolis se tornou município, passando a ostentar o título de cidade sem ter sido vila. Á época, Petrópolis era formada por somente dois distritos e, somente durante a República, houve a anexação de outros distritos (Lacombe, s.d).

Retomando o cenário de abertura dos novos caminhos que conduziriam às minas e à busca de novos refúgios da febre amarela, a Fazenda do Padre Correia acabou por servir de objeto de desejo de D. Pedro I em suas andanças e exploraçôes. Logo, ele e sua família se tornaram frequentadores assíduos da fazenda, em virtude do clima agradável, com vistas ao bem da saúde de sua filha, a princesa Paula. Como era de se esperar, o imperador tentou comprar a propriedade. No entanto, a proprietária, d. Arcângela Joaquina da Silva, irmã do Padre Correia, não cedeu à proposta do imperador, alegando que a propriedade estava carregada de vínculo familiar.

Assim, D. Pedro I, por indicação de d. Arcângela Joaquina, comprou as terras vizinhas, que pertenciam à Fazenda do Córrego Seco, adquirindo mais tarde, em 1830, um terreno que pertencia a Correia e também um sítio contíguo ao Córrego Seco, propriedade de Vicente Ferreira e Cunha (Silva, 2000). No entanto, os planos de D. Pedro I não se realizaram. A situação política de Portugal se apresentava muito instável e D. Pedro I foi obrigado a abdicar do poder no Brasil. A fazenda adquirida nunca foi vendida, pois ele mesmo se encarregou de hipotecá-la, fazendo com que fosse arrendada. Daí em diante, ela passou de arrendatário a arrendatário, por não contar com terras férteis e produtivas (Lacombe, 2007).

Não tendo a Casa Imperial condições para realizar o levantamento da hipoteca do falecido imperador, a situação foi levada à Assembleia Geral, sendo incluída, na Lei n. 108, de 26 de maio de 1840, uma autorização para o governo brasileiro arcar com a despesa de até 14 mil réis para comprar a Fazenda do Córrego Seco, a fim de não perdê-la para os credores de D. Pedro I (Lacombe, 2007). Assim, recuperada a Fazenda do Córrego Seco, foi dada a largada para a administração da propriedade. A Casa Imperial, coordenada pelo então mordomo-mor, 
Paulo Barbosa, tinha a obrigação de administrar os palácios do imperador. Em 1843, através do Decreto-lei n. 155, de 16 de março, D. Pedro II concedeu ao major Frederico Koeler o arrendamento da fazenda, sob a condição de que construísse um palácio, uma igreja e uma colônia de povoamento (Fridman, 2001). Foi nesse momento que se deu a fundação da cidade de Petrópolis.

São três os personagens considerados importantes na fundação da cidade de Petrópolis, como nos mostra Lacombe (s.d.): o mordomo Paulo Barbosa da Silva, o major Frederico Koeler e o visconde de Sepetiba. Por ter sido um projeto de cidade que envolveria uma colônia de povoamento e a construção de um palácio, Petrópolis ganhou duas administrações: a Superintendência da Fazenda Imperial, submissa ao mordomo, e a Diretoria da Colônia de Petrópolis, submissa ao presidente da província. Ambos os cargos eram ocupados pelo major Koeler, que esteve diretamente ligado ao projeto de colonização de imigrantes alemães em Petrópolis, com vistas à substituição gradativa da mão de obra escrava negra por mão de obra livre branca.

Nesse sentido, segundo Lacombe (s.d.), não foi a chegada dos colonos alemães em 29 de junho de 1845 a responsável pela fundação da cidade de Petrópolis, e sim o projeto de construção da cidade-palácio, que permitiu a vinda de mais brancos para aquele povoamento. Encarregado de conduzir um projeto de tão grande porte, Koeler, como arrendatário da Fazenda do Córrego Seco, apenas deu prosseguimento à prática do projeto de colonização de D. Pedro II, porém em outra localidade.

A construção do Palácio de Verão de Petrópolis começou em 1843, sendo concluída em 1856. Sua construção foi iniciada por Koeler e, em seguida, passou para as mãos dos arquitetos Joaquim Cândido Guilhobel e José Maria Jacinto Rebelo. A decoração interna ficou a cargo do Araújo Porto Alegre. Sua construção contou com os grandes nomes da Academia Imperial de Belas-Artes (Montalvão, 2005). Nessa época, além do próprio palácio, havia a Casa da Cozinha, a Dispensa, a Casa do Arquivo e a Casa da Superintendência, além da Casa dos Semanários - todas situadas nos fundos do palácio. Essas edificações serviam para a administração e o abastecimento do palácio, enquanto a Casa dos Semanários funcionava como dormitório para os trabalhadores.

O jardim do palácio foi projetado pelo botânico Jean Baptiste Binot e abrigava uma mescla de árvores de espécies nacionais e exóticas. Havia fontes de água e viveiros de aves raras estrangeiras para a apreciação particular do imperador (Montalvão, 2005). Na imagem a seguir, é possível visualizar o palácio e seu jardim. 
Figura 1. Vista da frente do Palácio Imperial e do jardim, com uma ponte sobre o rio Quitandinha em Petrópolis.

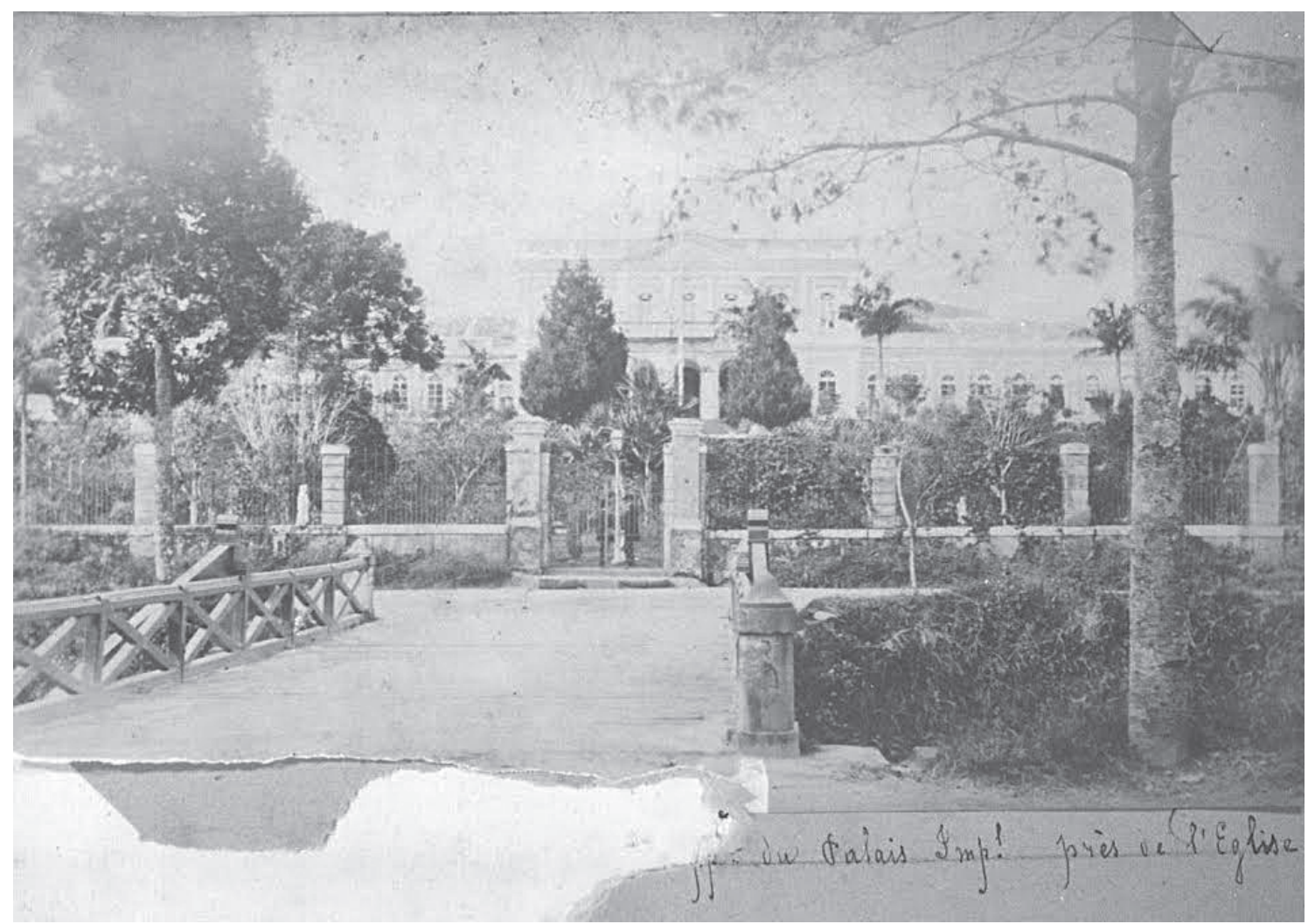

Fonte: Cópia concedida pelo Museu Imperial de Petrópolis para este trabalho. Requerimento de Autorização n. 17/2014, em 10/03/2014.

$\mathrm{Na}$ cidade de Petrópolis havia uma atmosfera de tranquilidade e prazer que permitia longos passeios pelos jardins, entre árvores exóticas. Quando lá estava, o imperador se hospedava em um de seus cômodos preferidos e bebia água da fonte. No entanto, por trás dessa atividade de veraneio, havia um projeto de cidade, um projeto de vida urbana. O palácio e seu jardim não serviram apenas como adereços ornamentais para o imperador; por trás desse projeto, eram irradiados os novos hábitos de uma prática social vinculada à vilegiatura.

Entendida em sua totalidade, Petrópolis era um espaço suburbano produzido pela vilegiatura e concebido como uma obra de arte (Ambrozio, 2005) - uma obra de arte da civilização. Assim, a fundação da cidade de Petrópolis integra o contexto de ocupação do interior fluminense, justificada pela busca do ouro e pela prática da vilegiatura. Lembramos que essa ocupação do interior se deu por meio do sistema de sesmarias, servindo como um dos novos caminhos para a exploração do ouro das Gerais. E, por ser uma cidade planificada, cujo polo central veio a ser a residência do imperador, o quarteirão da Vila Imperial - onde estavam o Palácio do Imperador e os demais equipamentos 


\section{Urbanismo imperial e planejamento dos barões}

coletivos - não deixa de evidenciar uma característica tão cara a esse momento inicial de ocupação e fundação de uma cidade-palácio, que vem a ser o processo de valorização do espaço na formação territorial brasileira. Um espaço valorizado em decorrência da produção do subúrbio vinculado à prática da vilegiatura e da recreação.

Nesse sentido, ao ser fundada, a cidade de Petrópolis tinha, em sua organização espacial, os ideais da corrente do higienismo e uma clara segregação socioespacial, vista pelo local de residência dos moradores de Petrópolis, que estava condicionado ao ofício e ao poder aquisitivo. O poder aquisitivo era o último fator determinante para o potencial de pagamento dos foros estabelecidos, além de forte indicador da posição a ser ocupada na escala social pelo respectivo residente. As residências mais próximas do palácio do imperador eram consideradas as áreas mais valorizadas e, portanto, pertenciam aos nobres mais prestigiados. Assim, seguindo uma ordem decrescente, os pobres ficavam mais afastados do palácio do imperador e de sua corte na organização do espaço interno da cidade de Petrópolis. O quarteirão da Vila Imperial era o ponto de destaque para a formação da cidade, e nesse local as classes socialmente menos abastadas não tinham vez.

Com ruas retilíneas, zonas especializadas segundo as profissóes de seus residentes e muitas praças para a circulação do ar, sem dúvida estamos falando de uma cidade planejada de acordo com os moldes da política higienista e preventiva. Referimo-nos aqui a uma segregação socioespacial promovida por um projeto de cidade-palácio cuja residência de um soberano acabou se revelando o ponto central para o ordenamento das classes sociais naquele espaço (Silva, 2000). Em virtude da possibilidade de as pessoas estarem mais próximas de D. Pedro II, com vistas à aquisição de algum privilégio político ou de receber investimentos em infraestrutura, como, por exemplo, a implantação de uma estrada de ferro pelo barão de Mauá, a cidade de Petrópolis se tornou um local de grande representatividade para figuras importantes do cenário político do Império.

A importância política de Petrópolis, devido à presença do imperador e de sua corte, fez com que seu tecido urbano se expandisse, com a construção de palacetes de propriedade de diplomatas e de figuras políticas do Império. Em alguns casos, as segundas residências foram transformadas em primeiras e, juntamente com essa expansão do tecido urbano, contribuíram também novos equipamentos urbanos instalados para atender às demandas da nova classe social (Schwarcz, 1998).

Desse modo, o tecido urbano petropolitano encheu-se de brilhantismo e pompa. Sua elegância e civilidade revelavam-se nos saraus, festas, bailes, teatros, concertos e conferências. Petrópolis unia uma vida bucólica e distante da cidade grande a uma vida social associada ao imperador (Schwarcz, 1998). A cidade também acolheu eventos sociais de corridas de cavalos, sediados no Jockey Clube de Petrópolis (1857); no Hipódromo de Petrópolis, localizado em Itaipava; no Prado Vila Teresa e no Delby Club, situados em Corrêas.

Para tornar Petrópolis uma cidade ainda mais requintada e moderna, foi construído, a mando da princesa Isabel, um Palácio de Cristal, para a realização de exposições de horticultura e também para sediar a primeira Exposição Universal, em 1851. A vida na cidade era repleta de costumes e hábitos palacianos, de tal modo que "Petrópolis representava, portanto, uma outra corte: repleta das atividades sociais, mas onde a distância do rei era atenuada por seu dia a dia um pouco menos marcado por uma agenda de compromissos e rituais oficiais" (Schwarcz, 1998, p. 244). 
No entanto, todo esse clima de civilização e recreação não duraria para sempre na Cidade de Pedro. A proclamação da República instauraria um novo regime na Cidade de Pedro, exilaria o último imperador das Américas e toda a sua família, e acabaria com nomes de ruas, símbolos e tudo o que remetesse ao ideário da Monarquia. Títulos de nobreza foram anulados, enquanto o imperador e sua família, desprovidos de todos os seus privilégios, eram sustentados por alguns amigos num país estrangeiro. Um monarca que tanto viajara pelo exterior com sua família, participando de exposições universais para promover sua pátria, já não se encontrava mais em casa. Contudo, o declínio da Monarquia no Brasil não enfraqueceu a cidade de Petrópolis, mantendo o status de cidade de veraneio para as figuras políticas importantes da República, que ainda se encantavam com o estilo de vida e os códigos sociais da Família Imperial Portuguesa (Montalvão, 2005).

As fases seguintes da República, do Estado Novo até o período de abertura democrática no Brasil, nos mostram Petrópolis como uma cidade que, em suas decadências e auges de determinadas atividades produtivas, como, por exemplo, a indústria e o turismo, sempre vai procurar construir e manter a grande marca de Cidade Imperial, fazendo com que, em seus planos diretores municipais e de revitalização, a Família Imperial Portuguesa e o modo de vida urbano instaurado se façam permanentemente presentes no imaginário popular.

Assim, o urbanismo imperial e o planejamento de barões, com seus respectivos ideais - o primeiro voltado ao higienismo e o segundo, à instalação da prática da vilegiatura -, estiveram muito presentes no contexto de ocupação da Região Serrana e da fundação da cidade de Petrópolis, que, nos sucessivos regimes políticos brasileiros, ainda manteve, por meio de uma política de preservação do patrimônio histórico e artístico nacional e de seus planos de revitalização do centro histórico, marcas das origens do processo urbanístico que se desenvolvia no país.

\section{Considerações finais}

Os pensamentos dos engenheiros militares e dos higienistas congregaram as muitas transformações na infraestrutura de várias cidades brasileiras, principalmente na cidade do Rio de Janeiro, que recebeu e irradiou muitas influências.

A chegada da Família Imperial Portuguesa ao Brasil representou as origens de um pensamento urbanístico brasileiro ainda em formação. A cidade do Rio de Janeiro, por sua vez, estava completamente aberta a receber essas ideias e técnicas avançadas. Assim, no desbravamento de novas rotas para o caminho do ouro e na fuga das epidemias que assolavam a cidade do Rio, surgiu a cidade de Petrópolis.

A Cidade de Pedro, ou Cidade-Palácio, para além de um projeto de colonização e de uma cidade pensada segundo os moldes higienistas para abrigar a corte e seu imperador em veraneio, foi uma cidade pensada e fundada, dando continuidade às bases do processo urbanístico que amadurecia no Brasil, na descoberta e na abertura de novos caminhos da Região Serrana fluminense. 
O urbanismo imperial e o planejamento dos barões se fundiam na cidade planificada de Petrópolis. Portanto, resgatar as bases de nosso processo urbanístico implica pensar as bases materiais de estratificação social segundo as quais nossas cidades se formaram e contribuir para o avanço das discussōes do pensamento urbanístico, recuperando, no tempo e no espaço, os vários pensamentos responsáveis à sua consolidação.

\section{Referências}

ABREU, Maurício de Almeida. A evolução urbana do Rio de Janeiro. Rio de Janeiro: Iplan-Rio, 1997. __. "Paradoxos da modernidade: o Rio de Janeiro do período joanino, 1808-1821". In FRIDMAN, F. e HAESBAERT, R. (orgs.). Escritos sobre espaço e história. Rio de Janeiro: Garamond, 2014, pp. 359-98.

—_. "Pensando o Brasil do passado". In FRIDMAN, F. e HAESBAERT, R. (orgs.). Escritos sobre espaço e história. Rio de Janeiro: Garamond, 2014, pp. 231-63.

AMBROZIO, Júlio César Gabrich. O presente e o passado no processo urbano da cidade de Petrópolis: uma história territorial (tese). USP, 2008.

ANDRADE, Francisco de Paula Dias. Subsídios para o estudo da influência da legislação na ordenaçãa e na arquitetura das cidades brasileiras (tese). USP, 1966.

FERNANDES, Nélson da Nóbrega. "Capitalismo e morfologia urbana na longa duração: Rio de Janeiro (século XVIII-XXI)". Diez años de cambios en el Mundo, en la Geografía y en las Ciencias Sociales, 1999-2008. 26-30 de mayo de 2008. Actas del X Coloquio Internacional de Geocritica, Universidad de Barcelona. Disponível em: http://www.ub.es/geocrit/-xcol/144.htm.

FRIDMAN, Fania. "De núcleos coloniais a vilas e cidades: Nova Friburgo e Petrópolis". Disponível em: http://www.anpur.org.br/revista/rbeur/index.php/anais/article/view/2187. Acesso em: 14 mar. 2014.

_. "Uma cidade nova no Rio de Janeiro". Encontro da Associação Nacional de Pós-Graduação e Pesquisa em Planejamento Urbano e Regional, 13, 25 a 29 de maio de 2009, Florianópolis. Disponível em: http://linux.an.gov.br/seer/index.php/info/article/view/73/56. Acesso em: 15 set. 2014.

LACOMBE, Américo Jacobina. "Paulo Barbosa e a Fundação de Petrópolis". Centenário de Petrópolis. Trabalhos da Comissão. Petrópolis, s.d., v. II.

LACOMBE, Lourenço Luiz. Biografia de um palácio. Petrópolis: Museu Imperial, 2007.

MONTALVÃO, Claudia Soares de Azevedo. Do Paço ao Museu: o Museu Imperial e a instituição da memória da monarquia brasileira (1940-1967) (tese). UFRJ, 2005.

SCHWARCZ, Lilia Moritz. As barbas do imperador: D. Pedro II, um monarca nos trópicos. São Paulo: Companhia das Letras, 1998, p. 239.

SILVA, Agnaldo Goivinho da. Petrópolis: idealismo e inovaçôes na gênese de uma cidade no Brasil-Império (dissertação). UFRJ, 2000. 